\title{
Migração e Sofrimento Psíquico do Trabalhador da Construção Civil: uma Leitura Psicanalítica
}

\author{
HÉLIA BORGES
}

ANDRÉ MARTINS ${ }^{2}$

Este texto propõe uma reflexão teórica sobre a associação de migração, trabalho e produção de patologias na população de trabalhadores da construção civil, sob uma ótica etológica e psicanalítica. Buscamos desenvolver uma interpretação dos aspectos afetivos da subjetividade envolvida no sofrimento psíquico desses trabalhadores, em sua grande maioria migrantes. Acuados pela diferença cultural, idealizam a cultura daquele que lhes dá emprego, ainda que as condições ambientais, simbólicas e culturais do novo lugar e do novo trabalho lhes sejam desfavoráveis e hostis. Concluímos que uma revolta muda e impotente do trabalhador contra essa hostilidade psíquica vivida se expressa, por deslocamento, no sentido psicanalítico do termo, através de seu sofrimento psíquico e físico.

Palavras-chave: Migração; patologia; trabalhador da construção civil; sofrimento psíquico; psicanálise. 


\section{Introdução e Apresentação do Problema}

Qual a influência que a migração pode exercer sobre o sofrimento dos migrantes trabalhadores da construção civil? Em que a imigração pode agravar o sofrimento psíquico desses trabalhadores? Procuramos abordar essas questões a partir de uma reflexão psicanalítica sobre o tema da imigração em sua interface com o trabalho.

Trabalho psicológico realizado de 1995 a 1998, junto aos trabalhadores da construção civil da cidade do Rio de Janeiro, nos quadros do Serviço Social da Indústria da Construção Civil do Rio de Janeiro (Seconci-RJ), instituição que pertence aos sindicatos da indústria e dos trabalhadores da construção civil (Sinduscom e Sintraconst), nos serve de base para as reflexões teóricas e interpretativas que ora apresentamos. Durante os quatro anos de trabalho, pudemos nos confrontar com, presenciar e testemunhar, enquanto psicanalistas, o sofrimento psíquico dos trabalhadores, e avaliar, a partir de nossa presença privilegiada, e regular em meio a eles, em seu local de trabalho, a importância dos elementos afetivos e da idealização envolvidos em suas relações com o novo ambiente.

Propomos aqui uma análise interpretativa dessas relações, a partir do instrumental teórico da etologia e da psicanálise. Nosso procedimento se apóia, portanto, em uma base dupla: nossa experiência junto ao grupo em questão como profissionais psicanalistas, e o material teórico, sobretudo etológico e psicanalítico, que orientou nosso trabalho, selecionado por adequar-se às situações vivenciais e simbólicas encontradas. Unindo experiência prática e instrumental teórico, procedemos à análise e às interpretações ora apresentadas.

Os agravos mais freqüentes na população de trabalhadores da construção civil - alcoolismo, doença mental, doença psicossomática, bem como os acidentes de trabalho - podem ser, sem dúvida, tomados como sintomas de seu sofrimento. Para compreendê-los, a dinâmica da organização do trabalho, com toda a certeza, deve ser analisada. Porém, também o deve o fato de que essa população, na sua maioria, é de migrantes, $81 \%$ oriunda do Nordeste (Klausmeyer, 1988). Será sobre os efeitos produzidos ou agravados pelo processo de migração na subjetividade dos trabalhadores que refletiremos aqui com maior atenção, propondo analisar a influência da migração sobre o modo como cada indivíduo migrante irá se apropriar de seu cotidiano na nova cidade e no novo trabalho, na construção civil. 
O processo migratório é característico da história humana no seu movimento expansivo. Porém, como em geral se dá de um local periférico para outro central, por questões econômicas, já vinculadas e mescladas a uma valoração do centro em detrimento da periferia, tal processo coloca o migrante diante de dois destinos que se entrecruzam: a riqueza do contato com a alteridade - própria e do outro -, para além de identidades fixas, e a exclusão associada ao desejo de inclusão. Nesse cruzamento se encontra a questão do migrante, em seu movimento para romper com a geografia traçada, na busca por novos territórios.

A exclusão que sofre o migrante, em função de ser portador de algo que resiste à representação dada na linguagem e no pensamento próprios à nova morada, nos remete à possível dissociação do sujeito humano, quando, para se instalar na cultura, abandona partes de si mesmo. Pois o trabalho, como atividade humana, se por um lado propicia ao homem satisfação, prazer, bem-estar, contribuindo para sua evolução, por outro se transforma, constantemente, em um espaço de sofrimento e exploração (Arendt, 1995).

Acompanhando a história humana, podemos observar as formas de captura impostas aos homens, no passado talvez mais evidentes, por exemplo, com a escravidão concretamente legitimada; no presente talvez menos evidentes, porém muito eficientes, através de sistemas de controle mais sofisticados (Foucault, 1979; Deleuze, 1990) - em um tempo em que "a mercadoria perdeu a forma concreta e se evaporou como um fantasma por toda a cultura", onde "o ritmo da produção e reprodução do capital é a que rege nosso desejo cotidiano, é a que forja nosso ser e nossas mediações abstratas e sem fim" (Ab'Saber, 2000).

Interessa-nos particularmente poder pensar acerca desses dispositivos de controle sobre o processo de produção da construção civil, tecendo uma reflexão que, implicando a migração, possa nos oferecer elementos para a construção de hipóteses concernentes às montagens que fazem os sujeitos a partir de suas particulares formas de apreender o mundo onde estão inseridos. A massificação dos indivíduos em lugares e valores preestabelecidos e uniformizados, através da violência simbólica acarretada pela imposição social de regras, aliena as pessoas de suas potencialidades criativas, aniquilando as diferenças, assimilando o diferente, anulando-o, traduzindo-o em um já conhecido. 
Propomo-nos a conduzir uma análise sobre alguns elementos do universo psíquico do migrado, refletindo sobre determinadas formas de subjetivação que são favoráveis aos mecanismos de exploração capitalista, em particular no que diz respeito aos operários da construção civil.

\section{Migração: aspectos psíquicos e etológicos}

Podemos dizer que, em termos psíquicos, o movimento migratório implica a noção de fragmentação de uma identidade. Ao se deixar um território, necessariamente entra em jogo a perda dos referenciais conhecidos. O processo de separação gera uma experiência de desamparo que na maioria das vezes é vivida como abandono.

Se, com a psicanálise (Winnicott, 1983) e a etologia (Cyrulnik, 1989; Stern, 1992), consideramos que a formação do psiquismo individual se dá em uma necessária imbricação com o ambiente, podemos formular algumas idéias sobre a formação de vínculos. Em relação às experiências de privação, o bebê só desenvolveria os sintomas de abandono, caracterizado pelas atividades autocentradas - como, por exemplo, balanceios, automanipulações da cabeça, mãos, braços, sexo etc. - se a experiência primeira de relação com a figura materna ficou vazia de contato, pela falta do estabelecimento do vínculo, por este não ter podido se dar, ou por ter se dado de modo vulnerável. Isso se deve não necessariamente à privação da figura materna, mas à falta de um cuidador que seja constante e se transforme numa referência inaugural, em que o mundo subjetivo possa se apoiar para que seu desenvolvimento ocorra. Neste sentido, em uma abordagem etológica, enfatizamos a importância do fenômeno do imprinting (Cyrulnik, 1989) - fenômeno caracterizado pelo registro interno no animal das imagens relativas ao cuidador nos seus primeiros momentos de vida - chamando atenção para a experiência do retorno do objeto, que asseguraria para o pequeno a experiência da continuidade e, portanto, a possibilidade de ligações posteriores com novos objetos de investimento, sejam eles indivíduos, sociedades, sistemas ou culturas.

Consideramos a cultura um conjunto de referenciais que permite, a cada membro de uma sociedade determinada, movimentar-se, expressar-se, pensar, amar, trabalhar, evitando o medo, se protegendo do desconhecido. Esses referenciais, que se encontram no ambiente, funcionarão como uma marca originária, promovendo os fundamentos para o desenvolvimento do psiquismo. 
Assim, o migrante tem que se haver com um processo de crise, pelas mudanças de códigos culturais, em que referentes conhecidos já não funcionariam mais, desfazendo um conjunto articulado de valores que lhe dão a necessária sustentação para o trânsito cotidiano. Podemos dizer, então, que dependendo da forma como o indivíduo estabeleceu seus vínculos originais com o ambiente, essas crises poderão ser ou não vividas de forma criativa.

\section{Duas Formas de Subjetividade: o nomadismo e a imigração}

Aqui lançamos mão da noção deleuziana de paradoxo (Deleuze, 1982), opondo-a aos dois sentidos da doxa: o bom senso e o senso comum. Deleuze nos propõe dois conceitos que dizem respeito a duas formas de distribuição: o de nômade e o de imigrado, que, no sentido conceitual que propõe, caracterizariam, respectivamente, um comportamento afirmativo de mudança de território, e um outro impregnado pela idéia de expulsão, que, de uma forma ou de outra, marca o processo migratório.

O migrante, sedentário, tipificado por Deleuze (1982), estaria na busca por uma identidade com o espaço novo, por via do assujeitamento ao novo espaço, à nova cultura e aos valores desta. Esse migrante procuraria se estabelecer, para fugir ao paradoxo, pela via do bom senso, pela instalação de cercados, pela afirmação numa só direção; a determinação dessa direção, partindo do mais para o menos diferenciado, do singular ao regular, do notável ao ordinário. Não há saída para o sedentário, segundo sua imaginação e seus fantasmas: ou se submete à nova ordem submetendo-se, ou se marginaliza na loucura.

Já a distribuição nômade, segundo a tipificação deleuziana, opera com a noção de paradoxo, assumindo-a, vivenciando-a, quando o sentido único dá lugar à impossibilidade de separar duas direções, passado-futuro, rompendo com o sentido, subvertendo-o, lidando e se constituindo a partir do imprevisível, reapropriando-se do novo, recriando-o. Aqui estaríamos nos aproximando das forças pulsionais, da potência do inconsciente, como possibilidade constituinte, fora do assujeitamento.

\section{Sobre o Alcoolismo}

A fuga do paradoxo e do aspecto imprevisível da vida aparece, ainda segundo um exemplo de Deleuze, no alcoolismo, como um processo de endurecimento do presente. O alcoólatra buscaria, no endurecimento do 
presente, uma forma de lidar com a fragilidade das paixões vividas. O alcoólatra poderia viver dois tempos: passado ou presente. A nostalgia do vivido se torna suportável apenas na sua onipotência maníaca proporcionada pelo álcool. Sabemos do número assustador de alcoólatras entre os imigrados do Nordeste, sobretudo naqueles que trabalham na construção civil. Esse efeito de suportabilidade da nostalgia pode ser referir à perda da terra de origem. $\mathrm{O}$ efeito-álcool, como forma de lidar com a perda, pois, representa ao mesmo tempo a terra - pois o inebriamento o faz esquecer a realidade atual e o transporta para a de suas fantasias - e a perda da terra - pois que na realidade é, da terra, apenas um substituto, um indício da terra que se perdeu, um representante seu, uma satisfação substitutiva, por um mecanismo de defesa.

A transformação operada pelo álcool sobre o peso do corpo, via fantasia de desaparição do corpo, permite denegar a experiência de privação que o imigrado já viveu e/ou vive, na qual o corpo é algo a ser vencido: alienando-se de suas necessidades, o indivíduo possibilita uma experiência imaginária de expansão e desdobramento que lhe parece se fazer necessária na chegada ao novo território, a fim de poder se localizar e se adaptar. Se a privação não é sentida em toda sua intensidade, ou melhor, se essa intensidade é anestesiada - pelo álcool, em geral - seu corpo parece se adaptar mais facilmente a ela. Para poder suportar a sensação de abandono experienciada quando sai em busca de um novo lugar, o trabalhador vivencia o abuso do álcool também como uma afirmação de comunhão ou continuidade com o outro, através do auto-erotismo envolvido no prazer proporcionado pelas drogas e do movimento fraterno característico do alcoólatra, que lhe proporciona uma quebra fácil de distâncias e uma aquisição de intimidade e companheirismo.

Deleuze \& Guatarri (1997) se perguntam: "Como sair do buraco negro? Como atravessar o muro? Como desfazer o rosto?", referindo-se à dificuldade, vivenciada de forma drástica pelo migrante, em se abandonar a memória, a consciência, o casal, a conjugalidade, romper com um ponto fixo e familiar. A diferença do nômade para o migrante também se localiza aí. O migrante se desterritorializa para se reterritorializar, vai de um ponto a outro, o ponto é o objetivo. Para o nômade, a distribuição se dá em espaços abertos, os pontos existem para serem abandonados.

As dificuldades de lidar com a perda, agravadas pela vulnerabilidade social do migrante, terminam por ser instrumentalizadas por uma manipulação e controle, por parte da sociedade, sobre os espaços e processos migratórios, 
através de leis e organizações que corroboram e lucram com o enfraquecimento do migrante, capturando os fluxos, uniformizando, procurando extinguir diferenças, fomentando identidades. A imposição de uma política globalizante, apoiada no consumo, no individualismo, opera de modo a impedir as divergências, o estranhamento, o novo, gerando no sujeito impotência, alienação de si e de valores que lhe sejam singulares, forçando-o a uma dura batalha para se afirmar, correndo o risco do enlouquecimento, da marginalização.

\section{Diferença, Familiaridade e Estranhamento}

Freud (1919) analisa os diversos significados do termo estranhamento em sua língua, demonstrando o caminho traçado entre heimlich e unheimlich: heimlich significando "familiar", e unheimlich, "sobrenatural", "estranho". Revela, nesse trajeto, a ambivalência presente: o estranhamento seria antes de tudo a negação do familiar. Porém, interpreta, uma negação que seria mais propriamente uma denegação do que, em mim, não quero aceitar, e projeto no outro. Uma denegação do familiar não desejado ou interdito, rejeitado como estranho, digno de repulsa. Familiar e estranho seriam sentidos opostos funcionando conjunta, paradoxalmente.

É na percepção da recusa desse outro familiar que se inscreve a experiência do migrante. Estranho é esse algo que mora no sujeito mas ao qual este não tem acesso consciente. Isto de alguma forma explicaria os sentimentos agressivos dirigidos à figura do estrangeiro, já que este seria portador de algo que não pertence aos referentes autorizados pelo novo território ocupado, acordando no sujeito que o recebe o medo da emergência em si mesmo de conteúdos recalcados. Repulsar o estrangeiro, o estranho, é uma forma de conjurar em mim aquilo a que ele me remete, mas que não quero conhecer. Aquilo que, não sendo valorizado pela cultura local, denegamos em nós.

Segundo Freud (1919), no fundamento do terror - que constantemente observamos nas violências cometidas por um ideal igualitário ou na defesa de projetos racistas - se encontraria um desejo de anulação da diferença, como um movimento de projeção para fora do eu, partes de si tidas como indesejáveis. Na realidade, esses ódios se voltariam contra um duplo de nós mesmos, algo que se quer eliminar em si, através da eliminação do outro no qual identificamos esse algo que nos é próprio. 
Alertados desse motor psíquico, dessa armadilha defensiva de nosso psiquismo, podemos, ao contrário, aceitar a diferença, explorando nossa potência criadora, a partir da potência criadora trazida pelo diferente. Explorar, através desse outro diferente, nosso mundo interno. Esse retorno sobre si mesmo não implicaria alienação do mundo externo, mas, ao contrário, a aceitação da importância das afetações provocadas em nós pelos encontros e interações com os objetos que nos atingem desde fora, num movimento constante de autosuperação.

\section{Desvalorização Cultural}

A migração produz certas reações humanas que podem, portanto, se encontrar na maioria dos migrantes, independentemente do local de origem ou da ocupação que assumem no novo lugar. Tais reações sem dúvida se agravam pelas particularidades relativas aos trabalhadores da construção civil, não qualificados ou semiqualificados, do Brasil e em particular do Sudeste, oriundos do Nordeste.

Característica dessa população de operários, a migração nordestina ocorre, em geral, por esgotamento de recursos no próprio lugar de origem do migrante. Para esses trabalhadores, a experiência do exílio é vivida intensamente, em função das grandes dificuldades que o indivíduo encontra para se adaptar às novas circunstâncias. Quando nos aproximamos dos imigrados do Nordeste, principalmente na área da construção civil, o que nos impacta é o sentimento de humilhação espelhado em seu sofrimento. O nordestino olha para a cultura da cidade grande como a um deus superior que pode ao mesmo tempo devorá-lo ou protegê-lo da miséria, abandonado que está pelo exílio. Fugindo da privação em seu lugar de origem, confrontando a um novo lugar que pode agravar essa privação, ou salvá-lo.

Nesse processo de adaptação, além da precariedade material enfrentada, para o sujeito se instalar na nova cultura se torna necessário um relativo mas importante abandono interno das categorias referentes à sua cultura de origem, e sem a garantia de que poderá se instalar no novo código. Há sobretudo uma grande desvalorização de sua cultura de origem, que se sobrepõe ao preconceito que exclui o imigrado. Desvalorização, por parte da nova cultura, e introjeção dessa desvalorização por ele mesmo. A exclusão que sofre o migrante e a resistência da sociedade em aceitar o recém-chegado, com suas diferenças, 
reforçam o seu sentimento de desamparo.

A percepção de si do migrante como inferior perante os novos referenciais é discutida por Elias (1994) em pesquisa etnográfica realizada na Inglaterra, composta de dados oriundos de estudos estatísticos oficiais, relatórios governamentais, documentos jurídicos e jornalísticos, entrevistas e, principalmente, observação participante. $\mathrm{O}$ autor expõe o preconceito existente nos antigos moradores de uma comunidade contra os recém-chegados. Estigmatizados, estes são vistos como pessoas de menor valor humano e acabam por incorporar essa visão. O desequilíbrio de poder gera nos indivíduos do grupo desvalorizado sentimentos de baixa auto-estima, assim como uma vivência de inferioridade humana, levando conseqüentemente ao seu enfraquecimento individual e, por conseguinte, também enquanto grupo social.

\section{Saúde Mental e Migração}

Almeida Filho (2000), por sua vez, faz um levantamento da literatura relativa às consequiências econômicas e sociais do desenvolvimento capitalista, incluindo a urbanização e os movimentos migratórios como fatores que contribuem para o aumento de patologias mentais - tais como estresse, alcoolismo, drogadição e doenças mentais. Apesar das diferentes conclusões a que chegam os estudos revisados, observa, existe consenso em se considerar a migração fator importante na produção de sofrimento psíquico e patologias mentais.

Em nossa própria experiência, observamos a emergência de crises psicóticas e histéricas na população migrante. No caso da psicose, nossa hipótese é que, no estilhaçamento do conhecido, o sujeito pode se fragmentar. Na passagem de uma cultura a outra, o migrante é tomado pela estranheza e pelo duplo, posto que já deixou um espaço de referência e ainda não estabeleceu novas raízes. A fissura que se abre pode produzir um afastamento do mundo externo por parte do migrante, que se refugia no que restou de si mesmo. Segundo o psicanalista Charles Melman (1992), podemos reproduzir experimentalmente as condições da histeria: basta que um sujeito participe de uma comunidade na qual não possa autorizar sua origem. A partir daí, ele é levado a ocupar, em relação a essa comunidade, o lugar do outro, ou seja, o lugar onde deve renunciar e recalcar as expressões de seu desejo e, para se fazer aceitar, deve agradar, seduzir. $\mathrm{Na}$ análise dos processos subjetivos que o 
sujeito vivencia em função dos movimentos migratórios, vemos que o abandono de suas referências de origem o leva a desejar intensamente ser outro que não ele mesmo. O processo migratório favorece a histericisação do sujeito, na medida em que, na busca pela integração, o migrante se afastaria de sua própria filiação com o propósito de ser aceito; assim como sua psicotização, caso a perda dos referenciais seja vivenciada como uma grave perda do sentido de sua própria realidade.

\section{Condições de Trabalho na Construção Civil}

Vejamos algumas características da organização do trabalho na área da construção civil, a fim de possibilitar maior compreensão das implicações dos mecanismos de exploração nesse ambiente de trabalho e seus desdobramentos na produção de patologias.

O cotidiano de um canteiro de obras está marcado ao mesmo tempo pela diversidade, pela especificidade e pelo conjunto: a maioria das tarefas está implicada na dependência de um grupo de pessoas que realizam, ao mesmo tempo, tarefas diferentes. Uma tarefa depende da realização de outras, num continuum, assim como em geral o trabalho se realiza em conjunto, dependendo da ação de outros operários. Esta é uma dimensão fundamental para uma análise dos processos discrepantes que se colocam na realização das tarefas previstas. Os intercâmbios que se dão entre os trabalhadores não são, portanto, controláveis, e por isso mesmo não podem ser totalmente eficazes. Ou seja, o trabalho prescrito constantemente perde para o trabalho real, efetivo, pois que este estará sempre e inevitavelmente aquém daquele.

Seja pelo atropelo constante em função da quantidade de atividades, principalmente na fase das fundações, seja pelo próprio processo de trabalho estar marcado por riscos freqüentes impostos pela atividade, a quantidade de acidentes é muito elevada, o que vai exigir do operário, a partir de sua competência, a construção de métodos e técnicas improvisadas (trabalho real) visando a responder à demanda (trabalho prescrito).

Outro aspecto que nos chama a atenção para qualificar o trabalho prescrito como irrealizável consiste no fato de o trabalho manufatureiro ter uma dimensão bastante expressiva nesse tipo de atividade. O trabalho manual se impõe como efetivo colaborador na realização das tarefas. A maquinária é 
utilizada em alguns momentos do processo, tendo posição secundária frente à quantidade de tarefas artesanais que ocorrem numa construção.

Percebemos, então, que na construção civil o trabalho real está constantemente se impondo ao prescrito, quase como um modo de fazer específico desse métier. Observamos que a realidade do canteiro de obras mantém um cotidiano no qual, na maioria das vezes, são atos criativos que se apresentam com o objetivo de dar conta do inesperado. Os esforços dos trabalhadores em superar as contradições impostas pela realização de determinadas tarefas produzirão a atividade necessária para atingir as metas propostas pelo processo produtivo. Tais esforços de inteligência, elaboração e interpretação não dependem apenas de atos individuais, mas contam com uma coordenação que requer cooperação e confiança. Para que esse caminho seja possível, segundo Dejours (1994), é fundamental o reconhecimento dos pares e dos superiores. A conquista da identidade no campo social, mediada pela atividade do trabalho, passa pela dinâmica do reconhecimento. Se isto não ocorre, estratégias defensivas serão mobilizadas, objetivando a sobrevivência face às exigências das tarefas.

Observamos que, na construção civil, a falta de reconhecimento do trabalhador é uma constante, entre outras coisas, devido à sua desqualificação, seja porque este é facilmente substituível, seja por sua dependência em relação ao emprego, seja por ser um migrante. Resta então a esse sujeito fazer uso de estratégias defensivas que acabarão por colocar em risco sua saúde física e psíquica.

Ainda em relação à dinâmica organizacional, observamos que o canteiro de obras não é apenas local de trabalho, é também onde grande parte dos trabalhadores mora, principalmente em função da migração. Desta forma, criam-se extensões entre trabalho e vida privada.

Neste ponto, já entrando em considerações relativas à psicopatologia do trabalho, no que diz respeito ao poder, algumas questões se colocam quanto ao posicionamento desse trabalhador face a seu cotidiano. O nível de submetimento é considerável, principalmente por ser este o espaço que o acolhe, estando recém-chegado num ambiente estranho. Encontramos assim um trabalhador que, como estratégia de pertencimento, se estabelece inteiramente ocupado em sua vida mental pela organização do trabalho, o que o distancia de entrar em contato com suas necessidades e desejos. 
Cabe ressaltar que, embora o ambiente dos canteiros de obra, como alguns pontos da cidade, possam ser espaços de acolhimento ao migrado do Nordeste em função dos conterrâneos já instalados, a experiência de exclusão é ainda assim vivida por essa população. A partir das discriminações sofridas e das expectativas criadas, o migrante nordestino de baixa renda e sobretudo o que trabalha em canteiros de obras -, seja o que acolhe seus conterrâneos, seja o recém-chegado -, se coloca diante da cidade grande, como já vimos, com uma baixa auto-estima e com uma espera e expectativa em relação ao recebimento de créditos que possam apaziguar suas necessidades psíquicas. É importante notar que tal sentimento de desamparo se instala no seu mundo subjetivo, intensificando seu sofrimento, apesar da comunidade de conterrâneos. A organização do trabalho exacerba a condição de desamparo já própria do migrante.

Constatamos que a longa jornada de trabalho, por vezes estendida em horas extras, se coloca também como fator a ser considerado para a análise do sofrimento desse operário, que se vê tensionado em excesso, indo além de suas condições fisiológicas e psicológicas, no objetivo de atender às demandas, por uma garantia de emprego e melhor salário.

O fato constatado, de que o canteiro de obras é um espaço privilegiado para a produção de acidentes de trabalho, chama atenção para os mecanismos empregados por esses trabalhadores, visando a lidar com o medo e a ansiedade gerados pela possibilidade de ocorrência de acidentes. Dejours (1994), por exemplo, faz referência às estratégias coletivas de defesa utilizadas pelos operários, como o desafio ao risco na não-utilização, pelos trabalhadores, dos equipamentos de segurança (EPI, equipamentos de proteção individual). Além disso, acrescentamos a negação, por parte das regras de segurança, da diferença de códigos culturais, já que na sua maioria a população é migrante e tais regras não levam em conta as normas e simbolismos culturais do operário. Isso prejudica sua compreensão sobre a importância real da utilização dos EPI, assim como em relação a como utilizá-los. Notemos, enfim, que os próprios recursos utilizados para a segurança do trabalhador ignoram os aspectos psíquicos envolvidos na relação do trabalhador com o trabalho, banalizando as causas dos acidentes.

“Se os agentes / riscos são assumidos como peculiaridades 'naturalizadas' de objetos e meios de trabalho, descontextualizados das razões que se situam em sua origem, repetem-se, na prática, as limitações da Medicina do Traba- 
lho. As medidas que deveriam assegurar a saúde do trabalhador, em seu sentido mais amplo, acabam por restringir-se a intervenções pontuais sobre riscos mais evidentes. Enfatiza-se a utilização de equipamentos de proteção individual, em detrimento dos que poderiam significar a proteção coletiva; normalizam-se formas de trabalhar consideradas seguras, o que, em determinadas circunstâncias, conforma apenas um quadro de prevenção simbólica" (Minayo \& Machado, 1995, p. 23).

As características do processo produtivo da construção civil, como a alta rotatividade de mão-de-obra, a longa jornada de trabalho, a organização específica do canteiro de obras com seus alojamentos, os subempregos, a constante inoperância da legislação trabalhista, os riscos cotidianos, a falta de um sindicato organizado, entre outros, concorrem para o assujeitamento da pessoa do trabalhador, que silencia sua denúncia pela promessa de amparo.

\section{Luta e Captura: valores de quem?}

A organização sindical, que deveria funcionar como um atenuador da exploração de mão-de-obra, ao contrário, muitas vezes reproduz a política do opressor, tendendo a agravar as dificuldades dos trabalhadores, reforçando o sentimento de impotência frente aos mecanismos de exploração. A questão sindical é de extrema importância, que por si só necessitaria de um estudo exclusivo, dada a forma complexa e perversa como tem se estabelecido. Não acreditamos que uma sindicalização, por si só, tornaria viável a luta dos trabalhadores. Na prática, verificamos que, no sindicato da categoria, ocorre principalmente

“(...) a introjeção do poder repressivo por parte dos oprimidos. A maior dificuldade aqui reside no fato de que os sindicatos e partidos, que lutam em princípio para defender os interesses dos trabalhadores e dos oprimidos, reproduzem em seu seio os mesmos modelos patogênicos que, em suas fileiras, entravam toda liberdade de expressão e de inovação" (Guattari, 2000, p. 32).

Desta forma, os ideais de luta passam a ser utilizados como chavões para a manutenção dos cargos adquiridos dentro do sindicato, deixando o operário no desamparo de suas necessidades, o que, como aponta Guattari 
(2000), paralisa o processo de criação e de livre expressão. O autor nos mostra como a força do capitalismo se estende, ampliando seu domínio, infiltrando-se nas subjetividades, criando obstáculos para a expressão de processos singulares. Percebemos que as patologias dos trabalhadores da construção civil se fazem em um processo de sofrimento psíquico no qual o trabalhador migrante, para sobreviver, necessita abortar seus valores e, esvaziando-se, aliena-se de seu potencial criativo, passando a incorporar os valores do empregador, emperrando sua capacidade crítica, reproduzindo modelos que lhe são oferecidos.

Aparentemente domesticado, o trabalhador luta por ideais que não são próprios, que passam imaginariamente a ser próprios, por interferência das pressões ambientais. Acreditamos que a condição de migrante, portanto, só irá reforçar o assujeitamento que lhe é imposto no sistema produtivo, no qual o trabalho é por ele tomado como único referente, tornando-o assujeitado, impotente, despotencializado de sua capacidade de autonomia e de construção criativa. Toma como modelo aquele que crê ser seu salvador, o empregador, e assim, introjetando o poder repressivo do opressor, desejando ser como aquele que lhe oprime, expressa, por deslocamento, através de seu sofrimento físico e psíquico, sua revolta muda e impotente.

\section{Considerações Finais}

Quando nos aproximamos do imigrado que necessita abandonar suas terras por sua sobrevivência, vemos evidenciado seu sofrimento. $\mathrm{O}$ abandono que o imigrante realiza, em função da ambicionada aceitação pela nova ordem, reforça a experiência de desamparo porque, além da perda dos referenciais conhecidos, estes se tornam desvalorizados.

Diante do problema em lidar com a angústia desencadeada pela experiência de desvalorização de suas origens, o sujeito, na busca por filiação e proteção, tende a atribuir à nova comunidade uma função paterna de proteção, sofrendo assim uma dupla exigência: por um lado ele deseja, em busca de reconhecimento, atender às expectativas da nova comunidade, que assume para ele a figura de um pai adotivo, expectativas que não são poucas; e, por outro, espera ver atendida sua própria exigência de que o novo pai recompense sua frustração pelas perdas que teve por ele. Auto-exigência em ser aceito pelo outro, expectativa de que o outro reconheça seu sacrifício em agradar: o 
migrante tende a assumir uma postura humilde de demanda de proteção paternalista, em decorrência da própria vulnerabilidade de sua situação.

Nesse jogo de demandas, pudemos observar as alianças inconscientes forjadas entre o trabalhador e o empresário, em que o submetimento às regras estabelecidas pelas instituições na nova comunidade parece assegurar ao trabalhador que suas necessidades serão atendidas. Infantilização e submetimento (pela vulnerabilidade e fragilidade de sua situação de migrante e operário) diante de um poder de proteção anunciado: podemos entrever aqui a relação psíquica estabelecida diante de algumas instituições brasileiras que oferecem serviços à população, quando assumem características paternalistas e encontram naqueles que os recebem um submetimento devido à expectativa de serem apaziguados em seu desamparo.

Buscamos ampliar as perspectivas teóricas de compreensão das questões relativas ao sofrimento do trabalhador migrante e a alguns de seus desdobramentos, como as patologias por ele sofridas, propondo uma reflexão sobre as dinâmicas afetivas envolvidas em sua relação com o novo ambiente. Procuramos entender como os afetos e as experiências sensíveis estão implicados nos deslocamentos do homem, colocando em relevo os aspectos psíquicos que, no caso do trabalhador, subjazem os processos de engajamento no novo território. Acreditamos que a abordagem psíquica das relações do trabalhador para com o novo ambiente pode ser de grande contribuição para entendermos melhor as formas de subjetivação fomentadas por esse tipo de migração. Daí a importância de se incluir o que podemos chamar de linguagem dos afetos na análise do processo de exploração vivido pelo trabalhador da construção civil, que nos permite compreender de modo mais preciso o quanto esse trabalhador migrante se encontra fragilizado ao se instalar numa obra, tornando-se vulnerável aos mecanismos de exploração.

\section{Referências}

AB'SÁBER, T. Morra, Lola Morra. Folha de São Paulo, Caderno Mais, São Paulo, n. 486, junho 2000.

ALMEIDA FILHO, N. Epidemiologia social das desordens mentais: Revisão da literatura Latino-Americana. In: TUNDIS e COSTA (Org.). Loucura e cidadania. 6. ed. Petrópolis: Vozes, 2000. p. $103-131$. 
ARENDT, H. A condição humana. Rio de Janeiro: Forense Universitária, 1995.

BORGES, H. Processo migratório e saúde do trabalhador da construção civil: desterritorialização e estranhamento. Dissertação (Mestrado em Saúde Coletiva) - Faculdade de Medicina, Núcleo de Estudos em Saúde Coletiva, Universidade Federal do Rio de Janeiro, 2002.

CYRULNIK, B. Sous le signe du lien. Paris: Hachette, 1989.

DEJOURS, C. Psicodinâmica do trabalho. São Paulo: Atlas,1994.

DELEUZE, G. Lógica do sentido. São Paulo: Perspectiva, 1982. . Politique. Pourparlers. Paris: Minuit, 1990.

DELEUZE, G; GUATTARI, F. Mil platôs. São Paulo: Editora 34, 1997.

ELIAS, N. Os estabelecidos e os outsiders. Rio de Janeiro: Zahar, 1994.

FREUD, S. O estranho. Rio de Janeiro: Imago, 1994.

FOUCAULT, M. Microfisica do poder. Rio de Janeiro: Graal, 1979.

GUATTARI, F. As três ecologias. São Paulo: Papirus, 2000.

KLAUSMEYER, M. L. O peão e o acidente de trabalho na construção civil do Rio de Janeiro. 1988. Dissertação (Mestrado em Educação) Departamento de Filosofia da Educação. Fundação Getúlio Vargas, Rio de Janeiro, 1988.

MELMAN, C., Imigrantes, incidências subjetivas das mudanças de língua e de país. São Paulo: Escuta 1992.

MACHADO, J.M.; MINAYO-GOMEZ,C. Acidentes de trabalho: concepções e dados. In: MINAYO, M. C. S. (Org.). Os muitos Brasis: saúde e população na década de 80. São Paulo: Hucitec, 1995. p. 117-142.

MINAYO, C.; THEDIN, S. A construção do campo de saúde do trabalhador: percurso e dilemas. Cadernos de Saúde Pública, Rio de Janeiro, v. 13, p. 21 32, 1997.

STERN, D. O mundo interpessoal do bebê. Porto Alegre: Artes Médicas, 1992. 
WINNICOTT, D. W. O ambiente e os processos de maturação. Porto Alegre: Artes Médicas, 1983.

\section{NOTAS}

${ }^{1}$ Psicanalista, mestre em Saúde Coletiva pela Faculdade de Medicina e Núcleo de Estudos de Saúde Coletiva (NESC) da UFRJ; membro do Espaço Brasileiro de Estudos Psicanalíticos.

${ }^{2}$ Professor adjunto da Faculdade de Medicina e do Núcleo de Estudos de Saúde Coletiva (NESC) da UFRJ. Doutor em Filosofia pela Université de Nice, França; doutor em Teoria Psicanalítica pela UFRJ. 
Migration and Psychological Suffering in Brazilian Construction Workers: a psychoanalytical reading

This paper proposes a theoretical reflection on the association between migration, labor, and the production of diseases in construction workers from an ethological and psychoanalytical perspective. We attempt to develop an interpretation of the affective aspects of subjectivity involved in psychological suffering in these workers, the vast majority of whom are migrants. Intimidated by cultural difference, they idealize the employer's culture, although the environmental, symbolic, and cultural conditions of their new place and new work are unfavorable and hostile. We conclude that a mute and impotent revolt by workers against this psychological hostility is expressed by means of a displacement, in the psychoanalytical sense of the term, through their psychological and physical suffering.

Key words: Migration; disease; construction worker; psychological suffering; psychoanalysis.

Recebido em: 10/12/2003.

Aprovado em: 24/03/2004. 